\title{
Pharmacokinetics, radiation dosimetry, acute toxicity and automated synthesis of $\left[{ }^{18} \mathrm{~F}\right] \mathrm{AmBF}_{3}$-TATE
}

Joseph Lau', Jinhe Pan ${ }^{1,2}$, Etienne Rousseau', Carlos F. Uribe', Sudhakara Reddy Seelam², Brent W. Sutherland ${ }^{3}$, David M. Perrin ${ }^{4}$, Kuo-Shyan Lin ${ }^{1,2^{*}}$ and François Bénard ${ }^{1,2^{*}}$ (D)

\begin{abstract}
Introduction: $\left[{ }^{18} \mathrm{~F}\right] \mathrm{AmBF}_{3}-\mathrm{TATE}$ is a somatostatin agonist that selectively binds to somatostatin receptor subtype 2 (SSTR2). For clinical translation, pharmacokinetics, radiation dosimetry, and acute toxicity of $\left[^{18} \mathrm{~F}\right] \mathrm{AmBF}_{3}$-TATE were assessed with good laboratory practice (GLP) standards.

Methods: ICR mice were intravenously administered 0.8-2.0 MBq of $\left[{ }^{18} \mathrm{~F}\right] \mathrm{AmBF}_{3}-\mathrm{TATE}$, with one group pre-injected with $100 \mu \mathrm{g}$ of $\left[{ }^{19} \mathrm{~F}_{\mathrm{AmBF}} \mathrm{AmATE}_{3} 30 \mathrm{~min}\right.$ before radiopharmaceutical administration to assess uptake specificity. The mice were euthanized at 0.5, 1, 2, or $4 \mathrm{~h}$ post-injection (p.i.). Blood and tissues were collected, weighed, and counted on a gamma counter to determine percentage injected dose per gram (\%/D/g). Dosimetry was calculated based on biodistribution data using the mouse and human phantoms included in OLINDA. Acute toxicity was assessed in Sprague-Dawley rats at the dose of $0.742 \mathrm{mg} / \mathrm{kg}\left[{ }^{19} \mathrm{~F}\right] \mathrm{AmBF}_{3}-\mathrm{TATE}$, with a 14-day observation/recovery period. Blood chemistry parameters, gross, and histopathology were evaluated. Body weight change and food consumption were monitored. The production of $\left[{ }^{18} \mathrm{~F}\right] \mathrm{AmBF}_{3}$-TATE was automated on a Trasis AllinOne synthesis module.
\end{abstract}

Results: $\left[^{18} \mathrm{~F}\right] \mathrm{AmBF}_{3}$-TATE was cleared through the renal and hepatobiliary pathway. At $1 \mathrm{~h}$ p.i., the pancreas (F, 15.7 \pm 3.72 and $M 14.3 \pm 1.61 \% \mathrm{ID} / \mathrm{g}$ ), stomach $(F, 15.3 \pm 3.63$ and $\mathrm{M}, 19.0 \pm 3.49 \% \mathrm{ID} / \mathrm{g})$, and lungs $(F, 9.26 \pm 2.24$ and $\mathrm{M}, 6.17 \pm 6.04 \% \mathrm{ID} / \mathrm{g}$ ) were the organs with the highest specific uptake. Pre-injection with $\left[{ }^{19} \mathrm{~F}\right] \mathrm{AmBF}_{3}-\mathrm{TATE}$ significantly reduced pancreatic uptake ( $F, 0.13 \pm 0.03$ and $\mathrm{M}, 0.18 \pm 0.09 \% \mathrm{lD} / \mathrm{g})$ at $1 \mathrm{~h}$ p.i. For dosimetry extrapolated to the average adult human, the bladder $(0.027-0.030 \mathrm{mGy} / \mathrm{MBq})$, pancreas $(0.018-0.028 \mathrm{mGy} / \mathrm{MBq})$, and lungs $(0.006-0.013 \mathrm{mGy} / \mathrm{MBq})$ are expected to receive the highest doses. No test-item related effects were observed upon evaluation of clinical observations, body weights, food consumption, clinical pathology, gross pathology, and histopathology for acute toxicity. [ $\left.{ }^{18} \mathrm{~F}\right] \mathrm{AmBF}_{3}$-TATE was produced at activity yields of $15.6 \pm 4.59$ $\mathrm{GBq}$, average molar activity of $435 \pm 162 \mathrm{GBq} / \mu \mathrm{mol}$, and radiochemical purity of $98.0 \pm 1.73 \%$ with the automated synthesizer.

Conclusion: $\left[{ }^{18} \mathrm{~F}\right] \mathrm{AmBF}_{3}$-TATE binds specifically to SSTR2. At $1000 \times$ clinical dose, $\left[{ }^{19} \mathrm{~F}\right] \mathrm{AmBF}_{3}$-TATE was well tolerated with no treatment-related adverse effects.

Keywords: Positron emission tomography, Neuroendocrine tumors, AmBF 3 -TATE, Fluorine-18, Dosimetry, Toxicology

\footnotetext{
*Correspondence: klin@bccrc.ca; fbenard@bccrc.ca

${ }^{1}$ Department of Molecular Oncology, BC Cancer, Vancouver, BC, Canada

Full list of author information is available at the end of the article
}

\section{Springer Open}

(c) The Author(s). 2020 Open Access This article is licensed under a Creative Commons Attribution 4.0 International License, which permits use, sharing, adaptation, distribution and reproduction in any medium or format, as long as you give appropriate credit to the original author(s) and the source, provide a link to the Creative Commons licence, and indicate if changes were made. The images or other third party material in this article are included in the article's Creative Commons licence, unless indicated otherwise in a credit line to the material. If material is not included in the article's Creative Commons licence and your intended use is not permitted by statutory regulation or exceeds the permitted use, you will need to obtain permission directly from the copyright holder. To view a copy of this licence, visit http://creativecommons.org/licenses/by/4.0/. 


\section{Introduction}

Neuroendocrine tumors (NET) are low-incidence cancers that originate from the neuroendocrine system [1]. NETs can arise from many anatomical sites with approximately $70 \%$ of cases derived from gastrointestinal origin [1]. Because NETs tend to be indolent and slow growing, patients can be asymptomatic for years for non-secreting tumors. Consequently, a significant number of patients present with high tumor burden or metastatic disease at diagnosis [1]. Radiolabeled somatostatin analogs have been used as nuclear imaging agents as NETs commonly overexpress somatostatin receptor subtype 2 (SSTR2). Clinically used SSTR2-targeting positron emission tomography (PET) agents include, but are not limited to, $\left[{ }^{68} \mathrm{Ga}\right] \mathrm{Ga}$-DOTA-TATE, $\left[{ }^{68} \mathrm{Ga}\right] \mathrm{Ga}$-DOTATOC, and $\left[{ }^{68} \mathrm{Ga}\right] \mathrm{Ga}-\mathrm{NODAGA-JR} 11[2,3]$. These somatostatin analogs can be radiolabeled with beta-emitting radionuclides (e.g., lutetium-177) for peptide receptor radionuclide therapy $[4,5]$.

Recently, the Society of Nuclear Medicine and Molecular Imaging (SNMMI) penned an open letter to the US Food and Drug Administration (FDA) highlighting the shortage of good manufacturing practice (GMP)grade germanium-68/gallium-68 generators [6]. In the USA, the preparation of $\left[{ }^{68} \mathrm{Ga}\right] \mathrm{Ga}$-DOTA-TATE is approved with GalliaPharm ${ }^{\circ}$ generators (Eckert \& Ziegler), which expires after 550 elutions or 1 year and with Galli $\mathrm{Eo}^{\circ}$ generators (IRE ELiT), which expires after 450 elutions or 1 year. Despite the availability of germanium68 , the production capacity of these generators remains limited. Consequently, many academic sites within the USA are unable to supply $\left[{ }^{68} \mathrm{Ga}\right] \mathrm{Ga}$-DOTA-TATE, extending wait times for patients [6]. The demand for $\left[{ }^{68} \mathrm{Ga}\right] \mathrm{Ga}$-DOTA-TATE is expected to increase given the recent FDA approval of $\left[{ }^{177} \mathrm{Lu}\right] \mathrm{Lu}$-DOTA-TATE. To alleviate the shortage, the SNMMI proposed temporary exemptions to elution limit, approval of generators from different manufacturers, and adoption of cyclotron produced gallium-68 [6]. Whether or not these solutions will ensure adequate coverage for clinical demands remains to be seen.

An advantageous long-term solution may be the adoption of trifluoroborate-based somatostatin analogs [7]. Previously, our laboratory developed $\left[{ }^{18} \mathrm{~F}\right] \mathrm{AmBF}_{3}$-TATE, a somatostatin agonist that can be radiolabeled with fluorine-18 using a one-step isotope exchange reaction (Fig. 1) [8]. Fluorine-18 has advantages over gallium-68 including availability in large quantities from cyclotron (allowing imaging of more patients per synthesis), optimal imaging properties with a shorter positron range, and longer half-life that permits distribution from a centralized radiopharmacy to other institutions and imaging at later time points for optimal contrast. $\mathrm{AMBF}_{3}-\mathrm{TATE}$ has better binding affinity to SSTR2 than Ga-DOTATATE $\left(K_{\mathrm{i}}, 0.13 \pm 0.03\right.$ vs. $\left.0.7 \pm 0.2 \mathrm{nM}\right)$ [8]. Preclinical PET imaging data with $\left[{ }^{18} \mathrm{~F}\right] \mathrm{AmBF}_{3}$-TATE in AR42J

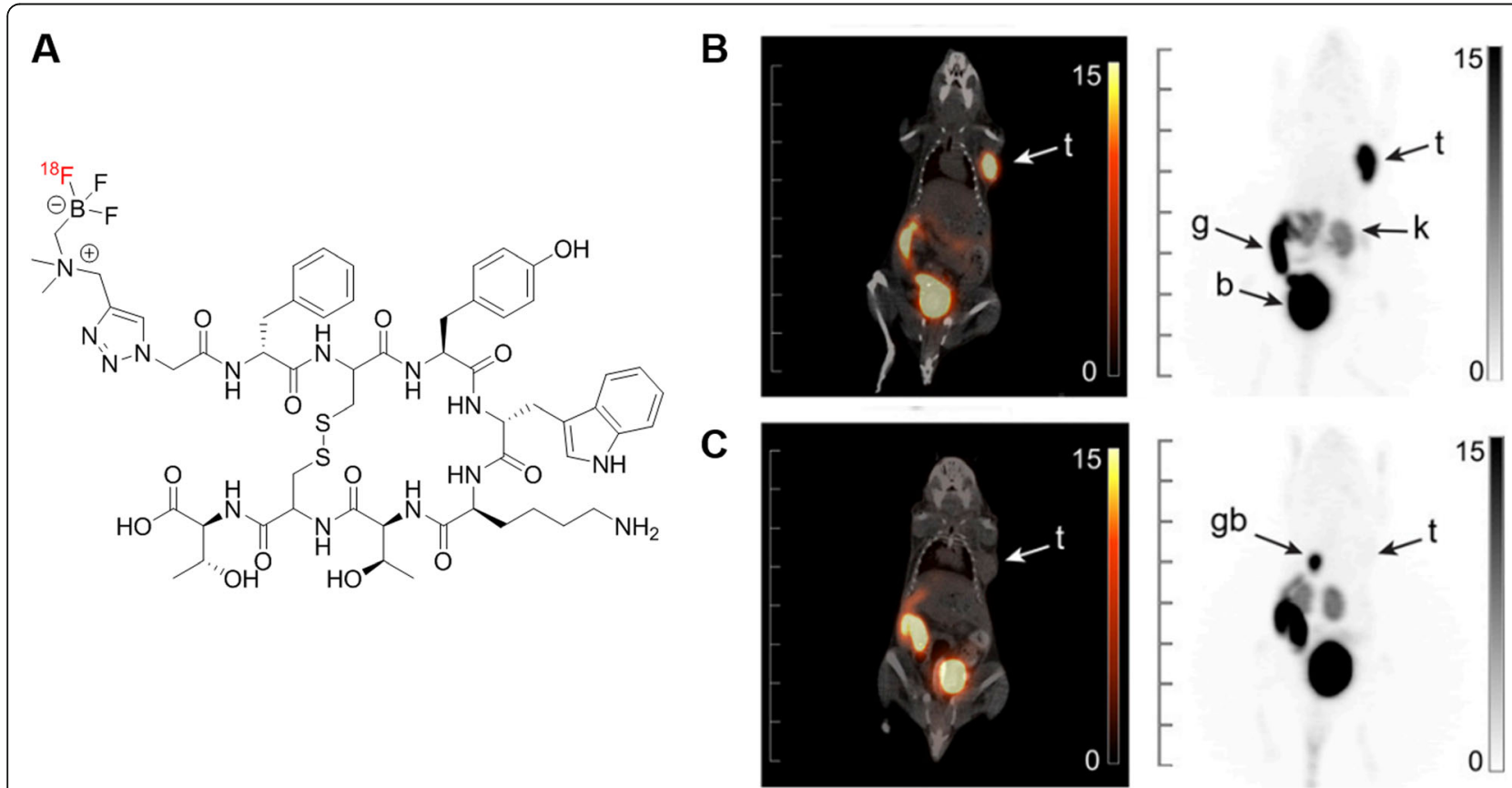

Fig. 1 a Chemical structure of $\left[{ }^{18} \mathrm{~F}\right] \mathrm{AmBF}_{3}$-TATE. $\mathbf{b}$ Baseline PET/CT and PET maximum intensity projection image of $\left[{ }^{18} \mathrm{~F}\right] \mathrm{AmBF}_{3}-\mathrm{TATE}$ acquired at 60-min post-injection in mice bearing AR42J exocrine pancreatic tumor and $\mathbf{c}$ with 15 min pre-injection of Ga-DOTA-TATE for blockade. $t$ tumor, $g$ gut, $k$ kidney, $b$ bladder, gb gallbladder. Figure adapted with permissions from Liu et al. Copyright 2014 Society of Nuclear Medicine and Molecular Imaging 
tumor xenograft-bearing mice showed rapid clearance from blood and liver, predominant urinary excretion, and high tumor uptake and high tumor-to-background contrast ratios [8].

For anticipated clinical translation, we evaluated the pharmacokinetics, radiation dosimetry, and acute toxicity of $\left[{ }^{18} \mathrm{~F}\right] \mathrm{AmBF}_{3}$-TATE in rodent models in accordance with good laboratory practice (GLP) regulations. Moreover, we implemented the synthesis of $\left[{ }^{18} \mathrm{~F}\right] \mathrm{AmBF}_{3}$-TATE on an automated synthesis module.

\section{Materials and methods Biodistribution study}

ICR mice (40 females and 40 males; $4-5$ weeks old) were purchased from Envigo. Following an institutional quarantine, mice were given a 1-week acclimatization period before randomization into treatment or blocking groups. Health statuses of the mice were monitored daily. $\left[{ }^{19} \mathrm{~F}\right] \mathrm{AmBF}_{3}$-TATE was custom ordered as a GLP qualified peptide $(\geq 95 \%$ purity $)$ from AmbioPharm. $\left[{ }^{18} \mathrm{~F}\right] \mathrm{AmBF}_{3}$-TATE was synthesized at the cyclotron radiopharmacy at $\mathrm{BC}$ Cancer, Vancouver, according to published procedures [8]. The mice (five groups: 0.5, 1 , 2,4 , and $1 \mathrm{~h}$ with blocking; eight females and eight males per group) were intravenously injected with $100-200 \mu \mathrm{L}$ of $\left[{ }^{18} \mathrm{~F}\right] \mathrm{AmBF}_{3}$-TATE at a dose of $0.5-2.0 \mathrm{MBq}$ through the lateral tail vein. Radioactivity measurements were performed on a Capintec CRC-25R dose calibrator. One group of mice received an intraperitoneal blocking dose of $\left[{ }^{19} \mathrm{~F}\right] \mathrm{AmBF}_{3}$-TATE $(100 \mu \mathrm{g}$ reconstituted in $200 \mu \mathrm{L}$ United States Pharmacopoeia (USP)-grade saline from Baxter) $30 \mathrm{~min}$ before radiopharmaceutical administration. Following uptake periods of $0.5,1,2$, or $4 \mathrm{~h}$, mice were euthanized by $\mathrm{CO}_{2}$ asphyxiation. Blood was promptly drawn via cardiac puncture, and any urine released was collected. Organs of interest (Additional file 1: Tables S1 and S2) were harvested, rinsed with PBS, patted dry, and collected into pre-weighed scintillation tubes. The samples were counted on a Perkin Elmer 2480 WIZARD2 gamma counter to determine the amount of radioactivity in liquids/tissues. After counting, the tubes were re-weighed to determine the mass by subtraction. Raw data was processed and presented as percent injected dose per gram of tissue (\%ID/g). All applicable institutional and/or national guidelines for the care and use of animals were followed, and the study protocol was approved by the institutional Research Ethics Board.

\section{Dosimetry}

The biodistribution data of $\left[{ }^{18} \mathrm{~F}\right] \mathrm{AmBF}_{3}$-TATE was decayed from injection to its corresponding time point. Mono-exponential and bi-exponential fits, for each of the organs, were performed in Python. The best fit was chosen based on the coefficient of determination $\left(R^{2}\right)$ and the residuals of the fit (Additional file 1: Figs. S1 and S2). Residence times were calculated from integration of the fitted time-activity-curves, scaled to the organ mass of the model chosen for dosimetry calculation (NURBS for human and $25 \mathrm{~g}$ MOBY for mice). The results were used as input in OLINDA v.2.0 (Hermes Medical Solutions) to obtain mouse dosimetry and extrapolated human dosimetry [9-12].

\section{Acute toxicity}

Acute toxicity studies were performed by NucroTechnics, Ontario Canada. Sprague-Dawley rats were ordered from Charles River (30 males and 30 females; 7-8 weeks old). After an acclimatization period of 8 days, rats were randomized into one of two studies: interim and main. Rats were intravenously administered $0.742 \mathrm{mg} / \mathrm{kg}$ of $\left[{ }^{19} \mathrm{~F}\right] \mathrm{AmBF}_{3}$-TATE (reconstituted with USP-grade saline from B Braun) or vehicle control. Animals were monitored twice daily during the recovery period for clinical signs. Animals in the interim study (20 males and 20 females) were euthanized by isoflurane 1 day post-treatment, while those in the main study (10 males and 10 females) were euthanized by isoflurane 14 days post-treatment. Prior to necropsy, blood samples were evaluated for hematological and chemical parameters, and urine samples were subjected to urinalysis. In addition to experimental control, baseline data used for comparison for clinical pathology parameters were taken from Nucro-Technics' historical database accounting for sex and age of the animals. Gross pathology analysis was performed immediately after euthanasia; organs of interest were harvested, fixed and preserved in $10 \%$ formalin, embedded in paraffin wax, and sectioned and stained by hematoxylin and eosin (H\&E). Tissues were examined microscopically by a pathologist. Body weights were recorded prior to dose, prior to necropsy, and weekly during the recovery period. Weekly food consumption was monitored for animals in the main study. Studies adhered to all applicable institutional and/or national guidelines for the care and use of animals.

\section{Automation \\ Reagents}

$\left[{ }^{19} \mathrm{~F}\right] \mathrm{AmBF}_{3}$-TATE was ordered from AmbioPharm Inc. Saline of USP grade and sterile water for injection were purchased from Baxter. Dimethylformamide (DMF), pyridazine, potassium hydrogen difluoride, and formic acid were purchased from Sigma-Aldrich. Hydrochloric acid for trace analysis was purchased from Honeywell. Ethanol was purchased from Commercial Alcohols. Acetonitrile was purchased from ThermoFisher Scientific. Ascorbic acid injection was purchased from Sandoz. 
No-carrier-added ${ }^{18} \mathrm{~F}$-fluorine was produced by bombardment of $\left[{ }^{18} \mathrm{O}\right] \mathrm{H}_{2} \mathrm{O}$ (Huayi Isotopes Co.) with 18$\mathrm{MeV}$ protons. Target irradiations were performed on a TR-19 cyclotron system (Advanced Cyclotron Systems Inc.) at the Department of Functional Imaging, BC Cancer Vancouver, Canada.

\section{Setup of automated synthesizer}

Production of $\left[{ }^{18} \mathrm{~F}\right] \mathrm{AmBF}_{3}$-TATE was conducted on a Trasis AllInOne module with 36 manifold actuators and an integrated HPLC system equipped with a Phenomenex Luna C-18 semi-preparative column $(100 \AA$, $10 \mu \mathrm{m}$, $10 \mathrm{~mm} \times 250 \mathrm{~mm}$ ). The cassette setup is shown in Fig. 2 with tubing connections, syringes, and other disposables. The cassettes were pre-assembled in a cleanroom using disposable materials supplied by Trasis. Luer lock syringes (Becton Dickinson) were secured at Positions 3 (3 $\mathrm{mL}), 9$, and $15(10 \mathrm{~mL})$. A Sep-Pak ${ }^{\bullet}$ Light Accell ${ }^{\mathrm{TM}}$ Plus QMA-Cartridge (Waters) preconditioned with $10 \mathrm{~mL}$ saline followed by $20 \mathrm{~mL}$ DI water and a Sep-Pak ${ }^{\circ}$ Light C18 Cartridge (Waters) preconditioned with $10 \mathrm{~mL}$ ethanol followed by $20 \mathrm{~mL}$ DI water were installed on Positions 5 and 33, respectively.

\section{Process description}

The target water containing ${ }^{18} \mathrm{~F}$-fluoride was transferred onto the module via a $20-\mathrm{mL}$ syringe body without a plunger attached to Valve 6 . The irradiated $\left[{ }^{18} \mathrm{O}\right] \mathrm{H}_{2} \mathrm{O}$ was passed through the QMA-cartridge in Position 5 into a vessel to trap the ${ }^{18} \mathrm{~F}$-fluoride onto the QMAcartridge, while the enriched water was recovered in vacuo. The ${ }^{18} \mathrm{~F}$-fluoride was eluted from the cartridge with $300 \mu \mathrm{L}$ saline (Position 2) using the syringe in Position 3 into the Reaction Vessel (Position 7) preloaded with an aqueous solution of $1 \mathrm{M}$ pyridazine and $2 \% \mathrm{HCl}$ ( $\mathrm{pH} 2,45 \mu \mathrm{L})$, DMF $(45 \mu \mathrm{L}), 5 \mathrm{mM}$ potassium bifluoride $(4 \mu \mathrm{L})$, and $\left[{ }^{19} \mathrm{~F}\right] \mathrm{AmBF}_{3}$-TATE precursor $(200 \mathrm{nmol})$. The reaction proceeded for $15 \mathrm{~min}$ at $85^{\circ} \mathrm{C}$ under vacuum (-1000 mbar). The reaction mixture was diluted with a solution of saline and $2.5 \mathrm{mg} / \mathrm{mL}$ ascorbic acid $(5.8 \mathrm{~mL})$ in Position 16 and loaded into the HPLC injection loop using the syringe in Position 9. $\left[{ }^{18} \mathrm{~F}\right] \mathrm{AmBF}_{3}$ TATE was purified by HPLC (Luna C-18 Column, 100 $\AA$, $10 \mu \mathrm{m}, 10 \mathrm{~mm} \times 250 \mathrm{~mm}, 23 \%$ acetonitrile with 100 ppm ascorbic acid, flow rate of $4.5 \mathrm{~mL} / \mathrm{min}$ ). The product peak was collected into a $50 \mathrm{~mL}$ vial in Position 17 and diluted with the solution of saline and $2.5 \mathrm{mg} / \mathrm{mL}$ ascorbic acid $(35 \mathrm{~mL})$ in Position 16 . The mixture was

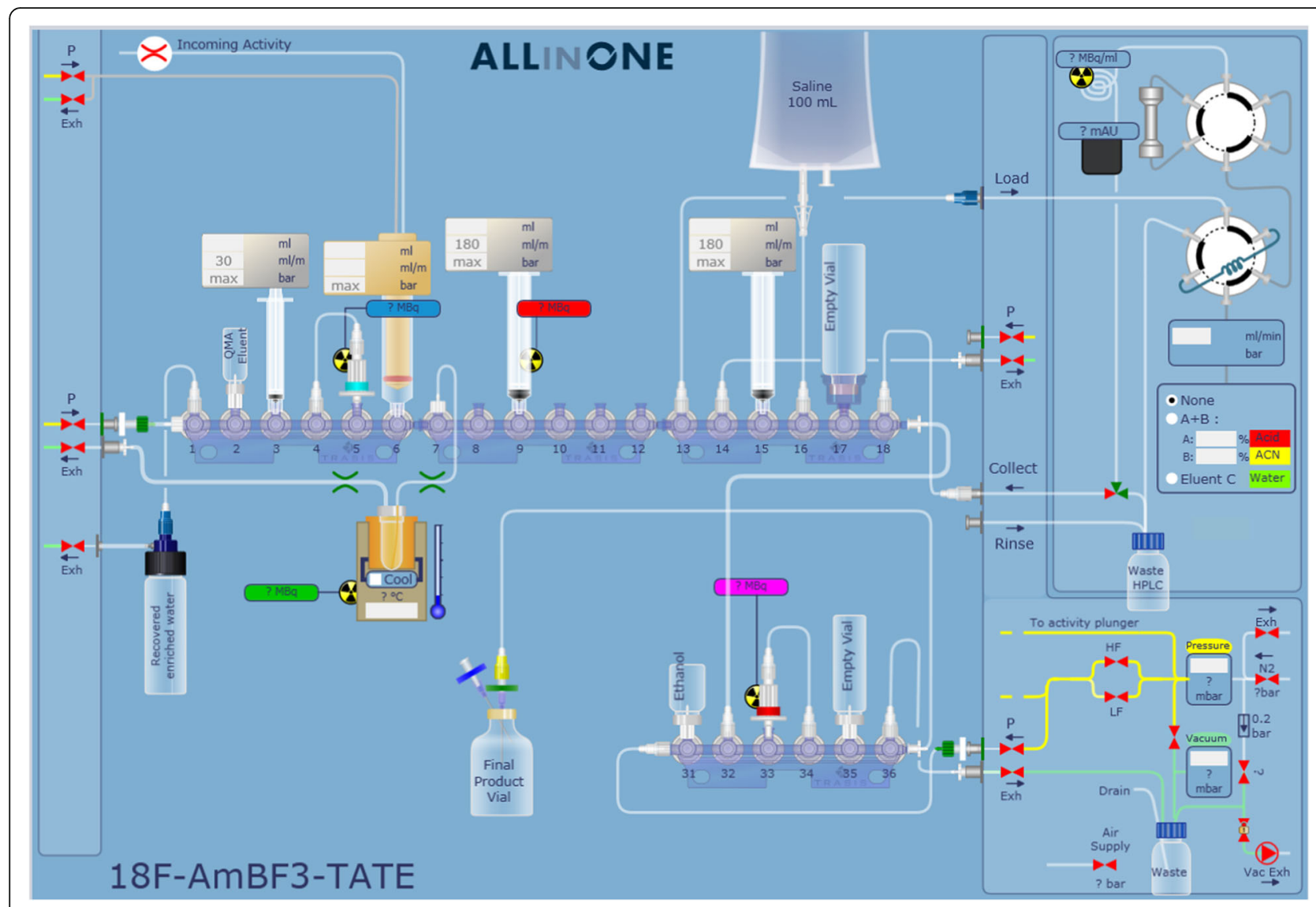

Fig. 2 Setup of the synthesis cassette to produce $\left[{ }^{18} \mathrm{~F}\right] \mathrm{AmBF}_{3}$-TATE with integrated HPLC purification on Trasis AlllnOne module 
passed through a C-18 cartridge in Position 33 using the syringe in Position 15. The C-18 cartridge was rinsed with a solution of saline and $2.5 \mathrm{mg} / \mathrm{mL}$ ascorbic acid $(10 \mathrm{~mL})$ in Position 16 , then $\left[{ }^{18} \mathrm{~F}\right] \mathrm{AmBF}_{3}$-TATE was eluted by ethanol $(1 \mathrm{~mL})$ in Position 31 into a $20 \mathrm{~mL}$ vial in Position 35 and diluted with a solution of saline and $2.5 \mathrm{mg} / \mathrm{mL}$ ascorbic acid $(16 \mathrm{~mL})$ in Position 16 using the syringe in Position 15. The solution was passed through a $0.2-\mu \mathrm{m}$ sterilizing filter (Merck Millipore) into a pre-sterilized product vial.

\section{Quality control (QC)}

Filter integrity was assessed using a bubble point test. The $\mathrm{pH}$ value of the formulation was determined by $\mathrm{pH}$ indicator strips (EMD Millipore). Residual solvents in the injection solution were measured by gas chromatography using a 7820A GC System with GC Chem Station software (Agilent Technologies). The radionuclidic identification was determined by half-life measurement using a Capintec CRC-25R dose calibrator. The concentration of ascorbic acid was determined by colorimetric assay using ascorbic acid test strips (Macherey-Nagel). The radionuclidic purity was measured by gamma spectroscopy using a high-purity germanium (HPGe) radiation detector with multichannel analyzer (Canberra). The HPGe detector was operated with the Canberra Genie 2.0 software. The limulus amebocyte lysate (LAL) test was conducted on an Endosafe ${ }^{\circ}$ PTS (Charles River Laboratories). Finally, a sample of the product formulation was tested for sterility post-release by an independent institution (Nucro-Technics) using direct inoculation in accordance with the USP monographs.

Calibrations of the HPLC systems were conducted by injection of $\left[{ }^{19} \mathrm{~F}\right] \mathrm{AmBF}_{3}$-TATE $(0.01,0.05,0.1,0.5$, and $1 \mu \mathrm{g})$, $\operatorname{DMF}(0.04,0.2,0.4,2$, and $4 \mu \mathrm{g})$, and pyridazine $(0.04,0.2$, $0.4,2$, and $4 \mu \mathrm{g}$ ) reference standards. HPLC analysis was performed on an Agilent HPLC system equipped with a model 1200 quaternary pump, a model 1200 UV absorbance detector (set at $220 \mathrm{~nm}$ ), a Bioscan NaI scintillation detector, and an analytical column (Luna C18, $5 \mu \mathrm{m}, 4.6$ $\mathrm{mm} \times 250 \mathrm{~mm}$ ) purchased from Phenomenex. The operation of Agilent HPLC systems was controlled using the Agilent ChemStation software. For analysis, a multi-step gradient was applied using Solvent A (0.1\% formic acid in water) and Solvent B (0.1\% formic acid in acetonitrile): Solvent $\mathrm{A}$ in the first $5 \mathrm{~min}$, then transitioning linearly to $76 \% \mathrm{~A}$ and $24 \% \mathrm{~B}$ over $1 \mathrm{~min}$, then held at $76 \% \mathrm{~A}$ and $24 \%$ $\mathrm{B}$ for $5 \mathrm{~min}$, then transitioning to $20 \% \mathrm{~A}$ and $80 \% \mathrm{~B}$ and over $3 \mathrm{~min}$, then to solvent A over $1 \mathrm{~min}$, and finally held at solvent A for $5 \mathrm{~min}$ (flow rate $=2 \mathrm{~mL} / \mathrm{min}$ ).

\section{Statistical analyses}

For biodistribution data, uptake in \% $\mathrm{ID} / \mathrm{g}$ is presented as mean \pm standard deviation. To examine target specificity, mice from 1-h time point and mice from 1-h time point pre-treated with the blocking agent were subjected to Student's $t$ tests (one-tail, unpaired) using Microsoft Excel 2007v. Group differences were considered significant at the level of $p \leq 0.05$.

For acute toxicity studies, data was collected using the Acentos preclinical software (PDS Inc.) and statistics were performed with the built-in function. Quantitative data is shown as mean \pm standard deviation, unless otherwise mentioned. The data for males and females were separately analyzed for equal variance and normality. Data that were normally distributed and had equal variance were analyzed using Student's $t$ test. If the normality or variance assumptions were not met, the analysis was performed with the non-parametric MannWhitney rank sum test. Group differences were considered significant if $p \leq 0.05$.

\section{Results \\ Biodistribution and pharmacokinetics}

The biodistribution data can be found in Fig. 3, Additional file 1: Tables S1 and S2. The organs with the highest specific uptake of $\left[{ }^{18} \mathrm{~F}\right] \mathrm{AmBF}_{3}$-TATE at the earliest examined time point $(30 \mathrm{~min}$ post-injection (p.i.)) were the pancreas (F, $30.5 \pm 5.64 \% \mathrm{ID} / \mathrm{g}$ and $\mathrm{M}$, $21.0 \pm 4.42 \% \mathrm{ID} / \mathrm{g})$, stomach $(\mathrm{F}, 27.9 \pm 2.20 \% \mathrm{ID} / \mathrm{g}$ and $\mathrm{M}, 18.8 \pm 3.73 \% \mathrm{ID} / \mathrm{g})$, and lungs (F, $11.2 \pm 2.68 \% \mathrm{ID} / \mathrm{g}$ and $\mathrm{M}, 6.56 \pm 4.50 \% \mathrm{ID} / \mathrm{g})$. The radioactivity in these organs gradually decreased at subsequent time points. In non-target tissues, the uptake of $\left[{ }^{18} \mathrm{~F}\right] \mathrm{AmBF}_{3}$-TATE was negligible at most time points examined. $\left[{ }^{18} \mathrm{~F}\right] \mathrm{AmBF}_{3}-$ TATE was rapidly cleared via the urinary and hepatobiliary tracts as evident by high and sustained levels of radioactivity in the urine at all time points examined (range, $105 \pm 129$ to $605 \pm 716 \% \mathrm{ID} / \mathrm{g}$ ) and gall bladder (range, $12.5 \pm 4.85$ to $35.3 \pm 19.8 \% \mathrm{ID} / \mathrm{g}$ ). The pharmacokinetics of $\left[{ }^{18} \mathrm{~F}\right] \mathrm{AmBF}_{3}$-TATE was very similar between the two sexes, with the noticeable exception of higher urinary bladder uptake in male mice at all time points.

To study target specificity of $\left[{ }^{18} \mathrm{~F}\right] \mathrm{AmBF}_{3}$-TATE, a group of animals were administered a blocking dose of $\left[{ }^{19} \mathrm{~F}\right] \mathrm{AmBF}_{3}$-TATE $30 \mathrm{~min}$ prior to radiopharmaceutical administration. For female mice, the uptake in the pancreas $(15.7 \pm 3.72$ vs $0.13 \pm 0.03 \% \mathrm{ID} / \mathrm{g} ; p<0.001)$, stomach $(15.3 \pm 3.63$ vs $0.23 \pm 0.05 \% \mathrm{ID} / \mathrm{g} ; p<0.001)$, and lungs $(9.26 \pm 2.24$ vs $0.54 \pm 0.16 \% \mathrm{ID} / \mathrm{g} ; p<0.001)$ were significantly reduced at $1 \mathrm{~h}$ p.i. compared to nonblocked group. This was also observed for male mice, as the uptake in the pancreas $(14.3 \pm 1.61$ vs $0.18 \pm 0.09$ $\% \mathrm{ID} / \mathrm{g} ; p<0.001)$, stomach $(19.0 \pm 3.49$ vs $0.26 \pm 0.08$ $\% \mathrm{ID} / \mathrm{g} ; p<0.001)$, and lungs $(6.17 \pm 6.04$ vs $0.61 \pm 0.14$ $\% \mathrm{ID} / \mathrm{g} ; p=0.02)$ were significantly reduced compared to non-blocked group. 


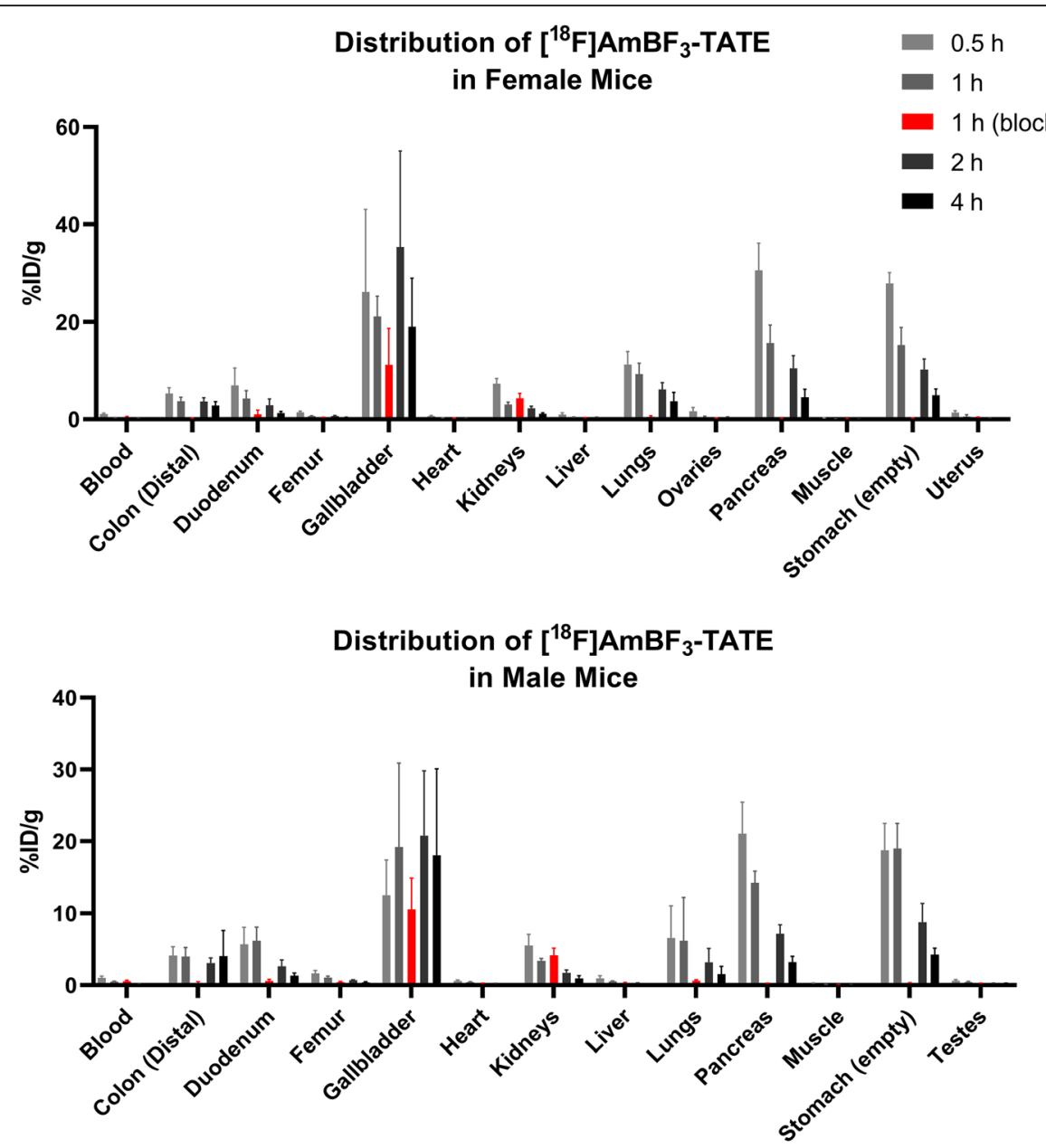

Fig. 3 Distribution of $\left[{ }^{18} \mathrm{~F}\right] \mathrm{AmBF}_{3}$-TATE in mice at selected time points. Blocking was performed with pre-injection of $100 \mu \mathrm{g}$ of $\left[{ }^{19} \mathrm{~F}\right] \mathrm{AmBF} 3^{-T A T E}$ 30 min before radiopharmaceutical administration

\section{Dosimetry estimations}

The absorbed doses in mice are shown in Additional file 1: Table S3, based on kinetic curves derived from biodistribution data (Additional file 1: Figs. S1 and S2). For both sexes, the organ that received the highest dose from $\left[{ }^{18} \mathrm{~F}\right] \mathrm{AmBF}_{3}$-TATE was the urinary bladder (F, $8.27 \mathrm{mGy} / \mathrm{MBq}$ and $\mathrm{M}, 10.5 \mathrm{mGy} / \mathrm{MBq})$. This was followed by the pancreas (F, $2.05 \mathrm{mGy} / \mathrm{MBq}$ and $\mathrm{M}$, $1.71 \mathrm{mGy} / \mathrm{MBq}$ ), intestines (range, $1.36-1.45 \mathrm{mGy} / \mathrm{MBq}$ ), and kidneys (F, 1.24 mGy/MBq and $\mathrm{M}, 1.13 \mathrm{mGy} / \mathrm{MBq}$ ). Aside from target and excretory organs, all other organs received less than $1 \mathrm{mGy} / \mathrm{MBq}$.

The estimated absorbed doses for an average adult human were extrapolated from mouse data and shown in Table 1. Consistent with the mouse model, the organ with the highest expected dose was the urinary bladder $\left(\mathrm{F}, 2.67 \times 10^{-2} \mathrm{mGy} / \mathrm{MBq}\right.$ and $\mathrm{M}, 3.02 \times 10^{-2} \mathrm{mGy} /$ $\mathrm{MBq})$. This was followed by the pancreas $\left(\mathrm{F}, 2.80 \times 10^{-2}\right.$ $\mathrm{mGy} / \mathrm{MBq}$ and $\left.\mathrm{M}, 1.81 \times 10^{-2} \mathrm{mGy} / \mathrm{MBq}\right)$, lungs (F, 1.27 $\times 10^{-2} \mathrm{mGy} / \mathrm{MBq}$ and $\left.\mathrm{M}, 6.25 \times 10^{-3} \mathrm{mGy} / \mathrm{MBq}\right)$, and stomach wall $\left(\mathrm{F}, 1.18 \times 10^{-2} \mathrm{mGy} / \mathrm{MBq}\right.$ and $\mathrm{M}, 8.14 \times$ $\left.10^{-3} \mathrm{mGy} / \mathrm{MBq}\right)$. The kidneys are expected to receive $6.69 \times 10^{-3} \mathrm{mGy} / \mathrm{MBq}$ in females vs $4.78 \times 10^{-3} \mathrm{mGy} /$ $\mathrm{MBq}$ in males.

\section{Acute toxicity}

No mortalities occurred during the study. All interim study animals were euthanized on day 2, as scheduled, and all main study animals completed the 14-day treatment-free recovery period and were euthanized as scheduled on day 15 (injections of test and control agents performed on day 1). For clinical observations, one male in the main study exhibited alocepia on both forelimbs on day 14 of the study, while the rest of the animals appeared normal throughout. Body weight change and food consumption were measured and shown in Table 2. At the end of recovery period, males in the treated group exhibited significantly decreased body weight gain when compared to the control group $(p<0.05)$. There were no other statistically significant 
Table 1 Estimated absorbed doses [mSv/MBq] for different organs in the average adult calculated with OLINDA software

\begin{tabular}{|c|c|c|c|}
\hline \multirow[t]{2}{*}{ Target organ } & \multicolumn{2}{|c|}{$\left[{ }^{18} \mathrm{~F}\right] \mathrm{AmBF}_{3}$-TATE } & \multirow{2}{*}{$\begin{array}{l}\left.{ }^{[68} \mathrm{Ga}\right] \mathrm{Ga}- \\
\text { DOTA- } \\
\text { TATE* }\end{array}$} \\
\hline & Female & Male & \\
\hline Adrenals & $5.87 \mathrm{E}-03$ & 4.84E-03 & $1.46 \mathrm{E}-02$ \\
\hline Brain & $1.62 \mathrm{E}-04$ & 1.61E-04 & $9.86 \mathrm{E}-03$ \\
\hline Breast & 7.73E-04 & - & $9.96 \mathrm{E}-03$ \\
\hline Esophagus & 2.10E-03 & 1.57E-03 & - \\
\hline Eye & $2.43 \mathrm{E}-04$ & $3.08 \mathrm{E}-04$ & - \\
\hline Gallbladder wall & $5.49 \mathrm{E}-03$ & $3.68 \mathrm{E}-03$ & 1.49E-02 \\
\hline Left colon & $6.29 E-03$ & $6.71 \mathrm{E}-03$ & $1.29 \mathrm{E}-02$ \\
\hline Small intestine & $8.43 \mathrm{E}-03$ & $6.20 \mathrm{E}-03$ & $1.38 \mathrm{E}-02$ \\
\hline Stomach wall & $1.18 \mathrm{E}-02$ & $8.14 \mathrm{E}-03$ & 1.38E-02 \\
\hline Right colon & $4.29 E-03$ & $3.68 \mathrm{E}-03$ & $1.29 \mathrm{E}-02$ \\
\hline Rectum & $5.91 \mathrm{E}-03$ & $4.22 \mathrm{E}-03$ & - \\
\hline Heart & $2.81 \mathrm{E}-03$ & $2.08 \mathrm{E}-03$ & 1.23E-02 \\
\hline Kidneys & $6.69 \mathrm{E}-03$ & 4.78E-03 & $9.21 \mathrm{E}-02$ \\
\hline Liver & $2.33 \mathrm{E}-03$ & 1.74E-03 & 4.50E-02 \\
\hline Lungs & 1.27E-02 & $6.25 \mathrm{E}-03$ & 1.15E-02 \\
\hline Ovaries & $2.45 \mathrm{E}-03$ & - & $1.31 \mathrm{E}-02$ \\
\hline Pancreas & $2.80 \mathrm{E}-02$ & $1.81 \mathrm{E}-02$ & 1.67E-02 \\
\hline Prostate & - & $2.66 \mathrm{E}-03$ & - \\
\hline Salivary glands & $7.32 \mathrm{E}-04$ & $9.24 \mathrm{E}-04$ & 1.17E-02 \\
\hline Red marrow & $1.28 \mathrm{E}-03$ & $1.02 \mathrm{E}-03$ & $9.61 \mathrm{E}-03$ \\
\hline Skeleton & $7.92 \mathrm{E}-04$ & 7.13E-04 & 1.55E-02 \\
\hline Spleen & 3.19E-03 & 2.07E-03 & 2.82E-01 \\
\hline Testes & - & $1.11 \mathrm{E}-03$ & 1.12E-02 \\
\hline Thymus & $6.08 \mathrm{E}-03$ & 4.20E-03 & 1.09E-02 \\
\hline Thyroid & $1.99 \mathrm{E}-03$ & $1.66 \mathrm{E}-03$ & 1.87E-02 \\
\hline Urinary bladder & 2.67E-02 & $3.02 \mathrm{E}-02$ & $1.25 \mathrm{E}-01$ \\
\hline Uterus & $4.50 E-03$ & - & $1.47 \mathrm{E}-02^{\#}$ \\
\hline Remainder of body & $1.49 \mathrm{E}-03$ & $1.04 \mathrm{E}-03$ & 1.34E-02 \\
\hline Effective dose & $5.91 \mathrm{E}-03$ & $4.36 \mathrm{E}-03$ & 2.57E-02 \\
\hline
\end{tabular}

*Reproduced with permission from Walker et al. [13]

"Uterus dosimetry was estimated as all scanned subjects were male findings in body weight, body weight changes, or food consumption between the treated and control groups during the study.

On occasion, individual values for hematology and clinical chemistry parameters were slightly outside the established normal reference ranges (data not shown). However, these values were also observed in the control group and therefore were considered incidental, not associated with other findings and of no toxicological significance. At the end of the interim study (day 2), treated males exhibited statistically significant decreases in several clinical chemistry parameters including serum albumin $(p<0.01)$, calcemia $(p<0.01)$, total protein $(p<$ $0.05)$, and natremia $(p<0.01)$ when compared to the control group. The decreases were mild, ranging from $2.0 \%$ to $6.9 \%$, and remained within the normal ranges except for natremia which was slightly above the normal range (136$143 \mathrm{mmol} / \mathrm{L})$ in both the treated $(144 \mathrm{mmol} / \mathrm{L})$ and control groups $(147 \mathrm{mmol} / \mathrm{L})$. At the end of the main study (day 15), treated females exhibited decreased hematocrit $(p<0.01)$ and increased calcemia $(p<0.05)$ compared to the control group. These changes were mild, $-4.4 \%$ and $+2.9 \%$, respectively, and remained within the normal ranges.

Aside from focal alopecia, gross pathology reported a treated rat had a cortical renal mass. Upon histopathological examination, it was interpreted that both findings were unrelated to treatment. Sporadic incidental findings of no general clinical consequence (inflammatory, developmental, degenerative, regenerative, proliferative) were observed histologically in small numbers of rats from both groups.

\section{Production of [18F]AmBF3-TATE on Trasis AllInOne Module}

The three production runs had activity yields of $15.6 \pm$ $4.59 \mathrm{GBq}$, decay corrected radiochemical yields of $15 \pm$ $4 \%$, molar activity of $435 \pm 162 \mathrm{GBq} / \mu \mathrm{mol}$, and radiochemical purity of $98.0 \pm 1.73 \%$ (Table 3 ). The average synthesis time following target bombardment was 60 min. All batches of $\left[{ }^{18} \mathrm{~F}\right] \mathrm{AmBF}_{3}$-TATE passed the QC parameters listed in Table 3. In terms of residual solvents, the average ppm value for ethanol was $44400 \pm$

Table 2 Summary of body weights, body weight changes, and food consumption during 14-day treatment-free recovery period

\begin{tabular}{|c|c|c|c|c|c|c|c|}
\hline \multirow[t]{2}{*}{ Group } & \multirow{2}{*}{$\begin{array}{l}\text { Dose } \\
(\mathrm{mg} / \mathrm{kg})\end{array}$} & \multicolumn{4}{|c|}{ Mean body weight $(\mathrm{g}) \pm \mathrm{SD}$} & \multirow{2}{*}{$\begin{array}{l}\text { Body weight } \\
\text { changes }(\mathrm{g}) \pm \\
\text { SD Days } 1-14 \\
(n=5)\end{array}$} & \multirow{2}{*}{$\begin{array}{l}\text { Mean food } \\
\text { consumption } \\
\text { (g) } \pm \text { SD Days } \\
1-14(n=5)\end{array}$} \\
\hline & & Day $1(n=15)$ & Day $2(n=10)$ & Day $8(n=5)$ & Day $14(n=5)$ & & \\
\hline $1-\mathrm{F}$ & 0 & $212.3 \pm 11.4$ & $197.0 \pm 10.9$ & $232.4 \pm 10.5$ & $242.2 \pm 13.2$ & $+30.2 \pm 8.9$ & $230.6 \pm 15.4$ \\
\hline $2-\mathrm{F}$ & 0.742 & $212.2 \pm 13.6$ & $195.4 \pm 11.3$ & $227.1 \pm 23.6$ & $240.9 \pm 19.7$ & $+29.3 \pm 4.7$ & $229.8 \pm 16.9$ \\
\hline $1-\mathrm{M}$ & 0 & $295.5 \pm 15.0$ & $265.8 \pm 14.1$ & $359.7 \pm 14.7$ & $403.2 \pm 21.1$ & $+108.1 \pm 14.8$ & $404.0 \pm 32.3$ \\
\hline $2-M$ & 0.742 & $297.2 \pm 17.2$ & $265.4 \pm 13.5$ & $358.0 \pm 21.1$ & $388.5 \pm 16.1$ & $+86.6 \pm 11.5^{*}$ & $365.7 \pm 19.4$ \\
\hline
\end{tabular}

*Significantly different from control group $(p<0.05)$ 
Table 3 Quality control (QC) of $\left[^{18} \mathrm{~F}\right] \mathrm{AmBF}_{3}$-TATE injection solution from three individual validation runs

\begin{tabular}{|c|c|c|c|c|c|}
\hline \multicolumn{3}{|l|}{ Run ID } & \multirow{3}{*}{$\begin{array}{l}\text { V- } \\
\text { ABT20190417A } \\
\text { 12.669 GBq } \\
\text { Results }\end{array}$} & \multirow{3}{*}{$\begin{array}{l}\text { V- } \\
\text { ABT20190430A } \\
13.240 \mathrm{GBq}\end{array}$} & \multirow{3}{*}{$\begin{array}{l}\text { V- } \\
\text { ABT20190508A } \\
20.890 \mathrm{GBq}\end{array}$} \\
\hline \multicolumn{3}{|l|}{ Batch size (GBq) } & & & \\
\hline Parameters & Method & Acceptance criteria & & & \\
\hline Filter integrity & Bubble point & $>50 \mathrm{psi}$ & Pass & Pass & Pass \\
\hline Appearance & Visual & $\begin{array}{l}\text { Clear, colorless to slightly yellowish solution; free of } \\
\text { visible particulates }\end{array}$ & Pass & Pass & Pass \\
\hline $\mathrm{pH}$ & $\mathrm{pH}$ indicator strip & $4.5-7.5$ & 5.5 & 5.5 & 5.5 \\
\hline \multirow[t]{5}{*}{ Residual solvents } & \multirow[t]{2}{*}{ GC-FID } & Ethanol: $<100,000$ ppm & $36,743 \mathrm{ppm}$ & $50,820 \mathrm{ppm}$ & 45,641 ppm \\
\hline & & Acetonitrile: < 400 ppm & $<10 \mathrm{ppm}$ & $<10 \mathrm{ppm}$ & $<10 \mathrm{ppm}$ \\
\hline & \multirow{2}{*}{$\begin{array}{l}\text { HPLC-UV- } \\
\text { radiometric }\end{array}$} & Dimethylformamide (DMF): < 880 ppm & $<1 \mathrm{ppm}$ & $<1 \mathrm{ppm}$ & $<1 \mathrm{ppm}$ \\
\hline & & Pyridazine: < 400 ppm & $<1 \mathrm{ppm}$ & $<1 \mathrm{ppm}$ & $<1 \mathrm{ppm}$ \\
\hline & Dose calibrator & Half-life: $105-115$ min & $112 \min$ & $109 \min$ & $110 \mathrm{~min}$ \\
\hline $\begin{array}{l}\text { Radiochemical } \\
\text { identification }\end{array}$ & $\begin{array}{l}\text { HPLC-UV- } \\
\text { Radiometric }\end{array}$ & $\begin{array}{l}t_{R} \text { of }\left[{ }^{18} \mathrm{~F}_{\mathrm{AMBMF}}-\text { TATE: } 100 \pm 10 \% \text { of the reference }\right. \\
\text { standard }\end{array}$ & $100 \%$ & $100 \%$ & $100 \%$ \\
\hline Radiochemical purity & $\begin{array}{l}\text { HPLC-UV- } \\
\text { radiometric }\end{array}$ & $\geq 90 \%$ & $99 \%$ & $99 \%$ & $96 \%$ \\
\hline Molar activity & $\begin{array}{l}\text { HPLC-UV- } \\
\text { radiometric }\end{array}$ & 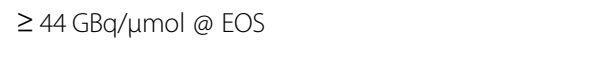 & $496 \mathrm{GBq} / \mu \mathrm{mol}$ & $251 \mathrm{GBq} / \mu \mathrm{mol}$ & $559 \mathrm{GBq} / \mu \mathrm{mol}$ \\
\hline Ascorbic acid & $\begin{array}{l}\text { Colorimetric } \\
\text { assay }\end{array}$ & $<20,000 \mathrm{mg} / \mathrm{L}$ & $1000 \mathrm{mg} / \mathrm{L}$ & $1000 \mathrm{mg} / \mathrm{L}$ & $1000 \mathrm{mg} / \mathrm{L}$ \\
\hline Bacterial endotoxins & LAL test & $<10.0 \mathrm{EU} / \mathrm{mL}$ & $<10.0 \mathrm{EU} / \mathrm{mL}$ & $<10.0 \mathrm{EU} / \mathrm{mL}$ & $<10.0 \mathrm{EU} / \mathrm{mL}$ \\
\hline Radionuclidic purity ${ }^{1}$ & $\begin{array}{l}\text { Gamma } \\
\text { spectroscopy }\end{array}$ & $\geq 99.5 \%$ & $100 \%$ & $100 \%$ & $100 \%$ \\
\hline Sterility ${ }^{1}$ & Post-release & Sterile, no growth & Pass & Pass & Pass \\
\hline
\end{tabular}

GC-FID gas chromatography flame ionization detector, $t_{R}$ retention time, EOS end of synthesis, LAL limulus amebocyte lysate

${ }^{1}$ These tests are done retrospectively

7100. Residual acetonitrile $(<10 \mathrm{ppm})$, dimethylformamide $(<1 \mathrm{ppm})$, and pyridazine $(<1 \mathrm{ppm})$ were undetected or below the limit of quantification (LOQ). The concentration of ascorbic acid present in the formulation was $1000 \mathrm{mg} / \mathrm{L}$. The formulations were sterile as no microbial contamination was observed in delayed testing. All additional tests were qualitatively passed or below LOQs. The representative radio-HPLC chromatograms of $\left[{ }^{18} \mathrm{~F}\right] \mathrm{AmBF}_{3}-\mathrm{TATE}$ are shown in Additional file 1: Figs. S3 and S4. $\left[{ }^{18} \mathrm{~F}\right] \mathrm{AmBF}_{3}$-TATE was stable for up to $6 \mathrm{~h}$ after end of synthesis (EOS) (Additional file 1: Fig. S5).

\section{Discussion}

The success of radiolabelled somatostatin analogs has been at the forefront of personalized medicine in nuclear medicine [14]. By changing the radioisotope of choice, SSTR2 ligands can be used effectively to diagnose, treat, and monitor response to treatment for NET patients. In the present study, we reported the biodistribution, pharmacokinetics, dosimetry, and automated production of $\left[{ }^{18} \mathrm{~F}\right] \mathrm{AmBF}_{3}$-TATE in anticipation for clinical translation.

We conducted a GLP-biodistribution study in ICR mice. Consistent with our previous studies, $\left[{ }^{18} \mathrm{~F}\right] \mathrm{AmBF}_{3}-$ TATE was cleared through the urinary and hepatobiliary tracts as evidenced by high and sustained levels of radioactivity in urine and gallbladder [8]. In male mice, higher urinary bladder uptake was observed at all time points. Organs that express SSTR2 including pancreas, lungs, and stomach showed high specific uptake of $\left[{ }^{18} \mathrm{~F}\right] \mathrm{AmBF}_{3}$-TATE as early as $30 \mathrm{~min}$ p.i. Pre-blocking with $\left[{ }^{19} \mathrm{~F}\right] \mathrm{AmBF}_{3}$-TATE significantly reduced uptake in SSTR2-expressing organs to near background levels, demonstrating target specificity of $\left[{ }^{18} \mathrm{~F}\right] \mathrm{AmBF}_{3}$-TATE. Unlike the previous study, we measured radiotracer uptake in stomach by emptying contents prior to counting. The uptake of $\left[{ }^{18} \mathrm{~F}\right] \mathrm{AmBF}_{3}$-TATE in non-target tissues was negligible at most time points. Since free ${ }^{18} \mathrm{~F}$-fluoride accumulates in the bone, uptake in the femur was used as a surrogate to determine defluorination in vivo. The uptake in the femur was $1.45-1.66 \% \mathrm{ID} / \mathrm{g}$ at $30 \mathrm{~min}$ p.i. and decreased continuously to $0.34-0.38 \% \mathrm{ID} / \mathrm{g}$ at $4 \mathrm{~h}$ p.i., indicating the product was stable against defluorination.

Based on dosimetry estimations, the organs that are expected to receive the highest absorbed doses are excretory organs (urinary bladder and intestines) or those that express SSTR2 (pancreas, lungs, and stomach). The estimated effective doses for $\left[{ }^{18} \mathrm{~F}\right] \mathrm{AmBF}_{3}$-TATE for the average adult female and male are $5.91 \mathrm{E}-03$ and $4.36 \mathrm{E}$ 
$-03 \mathrm{mSv} / \mathrm{MBq}$, respectively. Based on preclinical PET images of three mice, Lisova et al. calculated that the effective dose for $\left[{ }^{18} \mathrm{~F}\right] \mathrm{AmBF}_{3}$-TATE to be $1.16 \mathrm{E}-02$ to $1.26 \mathrm{E}-2 \mathrm{mSv} / \mathrm{MBq}$ [15], which is approximately $2-3$ folds higher. Given the differences in study design and sample size ( $n=80$ in present study), we believe our current study offers an accurate representation of $\left[{ }^{18} \mathrm{~F}\right] \mathrm{AmBF}_{3}$ TATE pharmacokinetics especially in organs that are difficult to identify/demarcate in preclinical PET images. For example, the dosimetry estimation for lungs in Lisova et al. may be underestimated due to cell/tissue density, partial volume effect and motion artifacts. As shown in Additional file 1: Tables S1 and S2, this organ expresses SSTR2 and uptake can clearly be blocked with pre-injection of the nonradioactive standard. From literature, the estimated effective doses for $\left[{ }^{68} \mathrm{Ga}\right] \mathrm{Ga}$ DOTA-TATE and 2-deoxy-2- $\left[{ }^{18} \mathrm{~F}\right]$ fluoro-D-glucose (FDG) are $2.57 \mathrm{E}-02$ and $1.92 \mathrm{E}-02 \mathrm{mSv} / \mathrm{MBq}$, respectively [13]. A patient receiving a $370 \mathrm{MBq}$ dose of $\left[{ }^{18} \mathrm{~F}\right] \mathrm{AmBF}_{3}$-TATE would receive between 1.61 and 2.18 $\mathrm{mSv}$. In comparison, patients will receive $4.75 \mathrm{mSv}$ from $\left[{ }^{68} \mathrm{Ga}\right] \mathrm{Ga}-\mathrm{DOTA}$-TATE $(185 \mathrm{MBq})$ or $7.02 \mathrm{mSv}$ from FDG $(370 \mathrm{MBq})$. It is important to note that the effective dose for $\left[{ }^{18} \mathrm{~F}\right] \mathrm{AmBF}_{3}$-TATE was extrapolated from mouse data, while the values provided for $\left[{ }^{68} \mathrm{Ga}\right] \mathrm{Ga}$ DOTA-TATE and FDG are derived from patient scans.

Acute toxicity of $\left[{ }^{19} \mathrm{~F}\right] \mathrm{AmBF}_{3}$-TATE was assessed in Sprague-Dawley rats in adherence to ICH guidelines. Rats were intravenously administered a single dose of $\left[{ }^{19} \mathrm{~F}\right] \mathrm{AmBF}_{3}$-TATE at $0.742 \mathrm{mg} / \mathrm{kg}$ and monitored for up to 14 days. The evaluated dose was $1000 \times$ the anticipated clinical dose, based on setting molar activity limit as $\geq 9.25 \mathrm{GBq} /$ $\mu \mathrm{mol}$ with a $370 \mathrm{MBq}$ dose for a $70-\mathrm{kg}$ patient at time of injection. No test-item-related effects were observed during the GLP toxicity study, upon evaluation of clinical observations, body weights, food consumption, clinical pathology, gross pathology, and histopathology. Weight gain was observed for all mice over the 14-day recovery period; however, males in the treated group exhibited significantly lower body weight gain compared to the control group. Peripheral administration of somatostatin can reduce food intake in rats $[16,17]$ and inhibits pituitary hormone secretion, including growth and adrenocorticotropic hormone secretion [18]; however, it is unclear why only males were affected in the present study. All other findings from clinical observations, hematology, clinical chemistry, gross pathology, and histopathology were considered incidental and of no clinical consequence. The data suggests $\left[{ }^{19} \mathrm{~F}\right] \mathrm{AmBF}_{3}$-TATE to be safe for administration.

We automated the radiolabeling process on a Trasis AllInOne module for good manufacturing practice (GMP)-compliant production. $\left[{ }^{18} \mathrm{~F}\right] \mathrm{AmBF}_{3}$-TATE was produced in good activity yields (12.7 to $20.9 \mathrm{GBq}$ ) and high average molar activity ( 251 to $559 \mathrm{GBq} / \mu \mathrm{mol}$ ), with each synthesis run taking $60 \mathrm{~min}$ on average. Based on a calculation of $370 \mathrm{MBq} /$ dose and accounting for decay and $30 \mathrm{~min}$ in between patient injections with a single scanner setup, we estimate this would amount to 8-10 individual patient doses from one production run. For the automation process, no additional effort was spent on reducing purification time or on optimizing radiochemical yield. We expect the activity yields will satisfy clinical demands; however, it is possible to further improve yield and/or molar activity by starting with higher levels of ${ }^{18}$ F-fluoride radioactivity from our experience with manual synthesis. All three validation runs of $\left[{ }^{18} \mathrm{~F}\right] \mathrm{AmBF}_{3}$-TATE passed $\mathrm{QC}$ parameters. Ascorbic acid was added to the formulation in order to prevent radiolysis of the radiopharmaceutical. Accordingly, no degradation of $\left[{ }^{18} \mathrm{~F}\right] \mathrm{AmBF}_{3}$-TATE in formulation was observed for up to $6 \mathrm{~h}$.

The impact of $\left[{ }^{18} \mathrm{~F}\right] \mathrm{AmBF}_{3}$-TATE would be significant; the longer half-life of ${ }^{18} \mathrm{~F}$ will enable distribution of the compound to centers that have no access to a cyclotron or a ${ }^{68} \mathrm{Ge} /{ }^{68} \mathrm{Ga}$ generator. For facilities that have a cyclotron, ${ }^{18} \mathrm{~F}$ would eliminate the need for purchasing an expensive generator that has a limited lifespan and elution capacity per day. Moreover, multiple patient doses can be prepared for $\left[{ }^{18} \mathrm{~F}\right] \mathrm{AmBF}_{3}$-TATE from a single production run, instead of two to four doses per batch for ${ }^{68} \mathrm{Ga}$-based somatostatin analogs. For daily clinical logistics, the superior half-life also allows greater freedom in the scheduling of patients and for dealing with unforeseen events that can delay imaging. Another important impact of the radiopharmaceutical lies in its superior imaging characteristics that could improve PET imaging accuracy of NETs. Due to a shorter positron range which allows for higher spatial resolution, improved receptor affinity, and low liver retention, we anticipate that $\left[{ }^{18} \mathrm{~F}\right] \mathrm{AmBF}_{3}$-TATE will be equal or superior to current ${ }^{68} \mathrm{Ga}$ labeled agents to detect small metastases. Moreover, the automated setup for production presented can be reused in centers with similar equipment, further facilitating access to the radiopharmaceutical, as no training in manual synthesis would be necessary.

The implementation of an ${ }^{18}$ F-labeled SSTR2 imaging radioligand can improve access to quality imaging for NET patients. A clinical trial application is planned to assess the safety and radiation dosimetry of $\left[{ }^{18} \mathrm{~F}\right] \mathrm{AmBF}_{3}$ TATE in NET patients.

\section{Conclusions}

$\left[{ }^{18} \mathrm{~F}\right] \mathrm{AmBF}_{3}$-TATE is a promising SSTR2 targeting pharmaceutical. In GLP studies with small animals, $\left[{ }^{18} \mathrm{~F}\right] \mathrm{AmBF}_{3}$-TATE showed rapid clearance from nontarget tissues leading to favorable dosimetry. $\left[{ }^{19} \mathrm{~F}\right] \mathrm{AmBF}_{3}$-TATE was well tolerated at $1000 \times$ clinical dose, suggesting an excellent safety profile. Lastly, the synthesis of $\left[{ }^{18} \mathrm{~F}\right] \mathrm{AmBF}_{3}$-TATE was automated to comply with regulatory guidelines for clinical translation. 


\section{Supplementary information}

Supplementary information accompanies this paper at https://doi.org/10. 1186/s13550-020-0611-9.

Additional file 1: Table S1. Biodistribution of $\left[{ }^{18} \mathrm{~F}\right] \mathrm{AmBF}_{3}-\mathrm{TATE}$ in ICR female mice at selected time points ( $n=8$ per group). Values reported in $\% \mathrm{ID} / \mathrm{g}$. Table S2. Biodistribution of $\left[{ }^{18} \mathrm{~F}\right] \mathrm{AmBF}_{3}$-TATE in ICR male mice at selected time points ( $n=8$ per group). Values reported in \%ID/g. Table S3. OLINDA-calculated dosimetry [mSv/MBq] using the $25 \mathrm{~g}$ MOBY mouse phantom from biodistribution data. Figure S1. Uptake of $\left[{ }^{18} \mathrm{~F}\right] \mathrm{AmBF}_{3}{ }^{-}$ TATE in female mice as a function of time for the bladder, blood, kidneys, liver, and pancreas. Figure S2. Uptake of $\left[{ }^{18} \mathrm{~F}\right] \mathrm{AmBF}_{3}$-TATE in male mice as a function of time for the bladder, blood, kidneys, liver, and pancreas. Figure S3. Radio-chromatogram of $\left[{ }^{18} \mathrm{~F}\right] \mathrm{AmBF}_{3}-\mathrm{TATE}$ acquired by the integrated HPLC system on the Trasis Allnnone module. Figure S4. QC Radio-chromatogram of $\left[{ }^{18} \mathrm{~F}\right] \mathrm{AmBF}_{3}$-TATE acquired by the Agilent HPLC system. Figure S5. Radio-chromatogram of $\left[{ }^{18} \mathrm{~F}\right] \mathrm{AmBF}_{3}$-TATE acquired by the Agilent HPLC system $6 \mathrm{~h}$ after EOS.

\section{Abbreviations}

DMF: DimethylformamideEOSEnd of synthesisFDAUS Food and Drug AdministrationGLPGood laboratory practiceGMPGood manufacturing practiceH\&EHematoxylin and eosinID/ginjected dose per gram of tissueLOQLimit of quantificationNETNeuroendocrine tumorPBSPhosphatebuffered salinePETPositron emission tomographyp.i.Post-injectionQCQuality controlSNMMISociety of Nuclear Medicine and Molecular ImagingSSTR2Somatostatin receptor subtype 2TATEOctreotate

\section{Acknowledgments}

The authors would like to acknowledge Guillaume Langlois and the Investigational New Drug Program at BC Cancer for their assistance with the study.

\section{Authors' contributions}

$J L, K S L$, and FB conceived and designed the complete study. JP and SRS were responsible for radiosynthesis and GMP automation. BWS was responsible for animal studies, while ER and CU performed dosimetry estimations. The manuscript was drafted by $J$ with critical revisions from DMP, KSL, and FB. All authors read and approved the final manuscript.

\section{Funding}

This study was funded by the Canadian Institutes of Health Research (PPP141710) and the BC Leading Edge Endowment Fund.

\section{Availability of data and materials}

The datasets used and/or analysed during the current study are available from the corresponding author on reasonable request.

\section{Ethics approval}

All applicable institutional and/or national guidelines for the care and use of animals were followed, and the study protocol was approved by the institutional Research Ethics Board.

\section{Consent for publication}

Not applicable.

\section{Competing interests}

Drs. Jinhe Pan, David M. Perrin, Kuo-Shyan Lin, and François Bénard are coinventors of a patent that covers $\left[{ }^{18} \mathrm{~F}\right] \mathrm{AmBF}_{3}$-TATE and the $\mathrm{BF}_{3}$ platform, and are shareholders of Alpha-9 Theranostics, which holds a license to the technology.

\section{Author details}

${ }^{1}$ Department of Molecular Oncology, BC Cancer, Vancouver, BC, Canada. ${ }^{2}$ Department of Functional Imaging, BC Cancer, Vancouver, BC, Canada. ${ }^{3}$ Department of Experimental Therapeutics, BC Cancer, Vancouver, BC, Canada. ${ }^{4}$ Department of Chemistry, University of British Columbia, Vancouver, BC, Canada.
Received: 30 December 2019 Accepted: 18 February 2020

Published online: 19 March 2020

\section{References}

1. Bodei L, Mueller-Brand J, Baum RP, Pavel ME, Hörsch D, O'Dorisio MS, et al. The joint IAEA, EANM, and SNMMI practical guidance on peptide receptor radionuclide therapy (PRRNT) in neuroendocrine tumours. Eur J Nucl Med Mol Imaging. Springer. 2013;40:800-16.

2. Hope TA, Bergsland EK, Bozkurt MF, Graham M, Heaney AP, Herrmann K, et al. Appropriate use criteria for somatostatin receptor pet imaging in neuroendocrine tumors. J Nucl Med. 2018:59:66-74.

3. Nicolas GP, Schreiter N, Kaul F, Uiters J, Bouterfa H, Kaufmann J, et al. Sensitivity comparison of 68Ga-OPS202 and 68Ga-DOTATOC PET/CT in patients with gastroenteropancreatic neuroendocrine tumors: a prospective phase II imaging study. J Nucl Med. 2018;59:915-21.

4. Strosberg J, El-Haddad G, Wolin E, Hendifar A, Yao J, Chasen B, et al. Phase 3 trial of 177 Lu-Dotatate for midgut neuroendocrine tumors. N Engl J Med. 2017;376:125-35.

5. Mansi R, Fani M. Design and development of the theranostic pair $177 \mathrm{Lu}-$ OPS201/ 68Ga-OPS202 for targeting somatostatin receptor expressing tumors. J Label Compd Radiopharm. 2019;62(10):635-45.

6. Cutler CS, Minoshima S. Open letter to FDA: shortage of germanium-68/ gallium-68 generators for the production of gallium-68. Soc Nucl Med Mo Imaging. 2018 [cited 2019 Jul 22]. Available from: http://snmmi.files.cmsplus.com/Ga68.shortage.letter.pdf.

7. Waldmann CM, Stuparu AD, van Dam RM, Slavik R. The search for an alternative to $[68 \mathrm{Ga}] \mathrm{Ga}-D O T A-T A T E$ in neuroendocrine tumor theranostics: current state of 18F-labeled somatostatin analog development. Theranostics. Ivyspring Int Pub. 2019;9:1336-47.

8. Liu Z, Pourghiasian M, Bénard F, Pan J, Lin K-S, Perrin DM. Preclinical evaluation of a high-affinity 18F-trifluoroborate octreotate derivative for somatostatin receptor imaging. J Nucl Med. 2014;55:1499-505.

9. Stabin MG, Sparks RB, Crowe E. OLINDA/EXM: the second-generation personal computer software for internal dose assessment in nuclear medicine. J Nucl Med. 2005;46:1023-7.

10. Keenan MA, Stabin MG, Segars WP, Fernald MJ. RADAR realistic animal model series for dose assessment. J Nucl Med. 2010;51:471-6.

11. Segars W, Tsui B, Lalush D, Frey E, King M, Manocha D. Development and application of the new dynamic Nurbs-based Cardiac-Torso (NCAT) phantom. J Nucl Med. 2001.

12. Stabin MG, Xu XG, Emmons MA, Segars WP, Shi C, Fernald MJ. RADAR reference adult, pediatric, and pregnant female phantom series for internal and external dosimetry. J Nucl Med. NIH Public Access. 2012;53:1807-13.

13. Walker RC, Smith GT, Liu E, Moore B, Clanton J, Stabin M. Measured human dosimetry of 68Ga-DOTATATE. J Nucl Med. 2013;54:855-60.

14. Werner RA, Weich A, Kircher M, Solnes LB, Javadi MS, Higuchi T, et al. The theranostic promise for neuroendocrine tumors in the late 2010s - where do we stand, where do we go? Theranostics. 2018;8:6088-100.

15. Lisova K, Sergeev M, Evans-Axelsson S, Stuparu AD, Beykan S, Collins J, et al. Microscale radiosynthesis, preclinical imaging and dosimetry study of [ 18 F]AMBF 3 -TATE: a potential PET tracer for clinical imaging of somatostatin receptors. Nucl Med Biol. 2018;61:36-44.

16. Lotter EC, Krinsky R, McKay JM, Treneer CM, Porter D, Woods SC. Somatostatin decreases food intake of rats and baboons. J Comp Physiol Psychol. 1981;95:278-87.

17. Aponte $G$, Leung $P$, Gross D, Yamada T. Effects of somatostin on food intake in rats. Life Sci. 1984;35:741-6.

18. Eigler T, Ben-Shlomo A. Somatostatin system: molecular mechanisms regulating anterior pituitary hormones. J Mol Endocrinol. 2014;53.

\section{Publisher's Note}

Springer Nature remains neutral with regard to jurisdictional claims in published maps and institutional affiliations. 